\title{
Optimalisasi Kinerja MGPS Pada Sistem Pendinginan di Kapal MT. Ketaling
}

\author{
Edgar $\mathbf{P}^{a}$, Nasri ${ }^{b}$, Ritonga, A.I ${ }^{\mathrm{c}}$

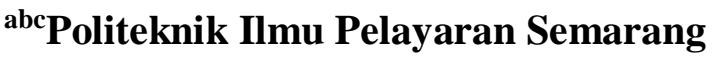 \\ aEmail: edgaryogipratama@gmail.com \\ bEmail: nasri@pip-semarang.ac.id. \\ 'Email: ali_imran@pip-semarang.ac.id
}

\begin{abstract}
ABSTRAK
Marine Growth Protection System (MGPS) merupakan permesinan anti fouling digunakan untuk mencegah pertumbuhan biota laut dan karat yang berlebih pada sistem pendingin air laut. Tujuan dari penelitian ini adalah untuk mengetahui faktor turunnya kinerja MGPS, dampak dari faktor, dan upaya yang dilakukan untuk mengoptimalkan kinerja MGPS. Metode yang digunakan dalam penelitian ini adalah kualitatif, dengan menggunakan teknik analisa data Fishbone dan SHEL. Fishbone digunakan untuk menganalisis kemungkinan faktor masalah dan kemudian menganalisis dan mengkategorikan prioritas masalah menggunakan teknik SHEL. Hasil penelitian dapat disimpulkan bahwa turunnya kinerja MGPS disebabkan oleh kurang tepatnya pengaturan tegangan, penggunaan anoda yang melebihi batas umur, kondisi atau unsur air laut, dan kurangnya pengetahuan seorang engineer. Hal tersebut berdampak pada turunnya kinerja MGPS pada sistem pendinginan di kapal. Untuk mengatasi faktor-faktor tersebut dapat dilakukan dengan pengoperasian dan perawatan permesinan MGPS harus berdasarkan pada manual book, mengganti anoda yang sudah melebihi batas umur, serta memberikan training kepada engineer tentang permesinan MGPS.
\end{abstract}

Kata Kunci: Sistem pendinginan, Marine Growth Protection System (MGPS), Anti Fouling.

\begin{abstract}
Marine Growth Protection System (MGPS) is an anti-fouling machine used to prevent excessive growth of marine biota and rust in the sea water cooling system. The purpose of this study was to determine the decline in MGPS performance factors, the impact of these factors, and the efforts made to optimize the performance of MGPS. The method used in this study is qualitative, using Fishbone and SHEL data analysis techniques. Fishbone is used to analyze possible problem factors and then analyze and categorize problem priorities using the SHEL technique. The results of the study concluded that the decline in MGPS performance was caused by inaccurate voltage regulation, the use of anodes that exceeded the age limit, sea water conditions or elements, and lack of knowledge of an engineer. This has an impact on the MGPS performance on the cooling system on the ship. To overcome these factors, operation and maintenance of MGPS machining must be based on a manual book, replace anodes that are over the age limit, and provide training to engineers about MGPS machining.
\end{abstract}

Keywords: Cooling system, Marine Growth Protection System (MGPS), Anti-Fouling.

\section{PENDAHULUAN}

Pada sebuah kapal dibutuhkan mesin penggerak utama agar dapat bergerak atau berpindah (Handoyo;
2015), dimana pada umumnya menggunakan air laut sebagai media pendingin pada sistem pendinginan untuk pesawat bantu, dan proses kondensasi di condenser. Pendingin adalah media yang 
berfungsi untuk menyerap panas. Panas tersebut berasal dari hasil pembakaran bahan bakar didalam cylinder maupun aktifitas mesin lainnya. Di dalam sistem pendingin terdapat beberapa komponen yang bekerja secara berhubungan antara lain: cooler, pompa sirkulasi air tawar, pompa air laut, strainer pada air laut, sea chest dan MGPS. Dari keenam komponen inilah yang dapat menyebabkan kurang maksimalnya hasil pendinginan terhadap motor induk (Maanen; 2002). Tujuan pendinginan adalah untuk menjaga temperatur agar stabil supaya mesin dapat bekerja terus menerus, mencapai tenaga yang maksimal, mengurangi terjadinya kerusakan mesin, mempertahankan temperatur agar bekerja dalam kondisi normal, dan agar daya tahan mesin atau bahan material lebih lama (NSOS; 2006).

Pada umumnya air laut yang digunakan sebagai media pendingin utama pada sistem pendinginan dan sistem kondensasi ini memiliki unsur bahwa $1 \mathrm{~kg}$ air laut rata-rata terdiri dari 9563 gram air tawar dan 34,7 gram garam (dan unsur lain). Selain itu air laut juga terdiri dari berbagai macam zat, diantaranya alkaline lemah yang mengandung sodium chloride yang tentu saja dapat merugikan dan merusak logam, besi atau sejenisnya dalam bentuk karat. Disamping itu tumbuh-tumbuhan dan hewan renik laut (organisme laut) seperti marine growth (Van Der Ham; 2003).

Karat merupakan hasil oksidasi suatu logam. Besi akan mengalami korosi menjadi karat dengan rumus $\mathrm{Fe}_{2} \mathrm{O}_{3} \cdot \mathrm{xH}_{2} \mathrm{O}$. Proses pengaratan atau korosi merupakan proses elektrokimia. Pada proses pengaratan, besi $(\mathrm{Fe})$ berperan sebagai pereduksi dan oksigen $\left(\mathrm{O}^{2}\right)$ yang terlarut dalam air berperan sebagai pengoksidasi. Berikut adalah proses persamaan reaksi pembentukan karat:

Anode $\left.: \mathrm{Fe}(s) \rightarrow \mathrm{Fe}_{2+}(a q)\right) 2 \mathrm{e}$.

Katode $: \mathrm{O}_{2}(g)+4 \mathrm{H}_{+}(a q)+4 \mathrm{e}_{-} \rightarrow$ $2 \mathrm{H}_{2} \mathrm{O}(l)$ (Gapsari; 2017).

MARINE GROWTH sendiri disebut sebagai sekelompok hewan atau tumbuhan laut yang tumbuh dan hidup berkoloni di permukaan bangunan di dalam laut, dimana kondisi suhu, bahan makanan/nutrisi, faktor ph (derajat keasaman) dan kondisi lingkungan lain cocok bagi pertumbuhan mereka (Hernandar; 2009).

Oleh karena itu dibutuhkan pesawat bantu Marine Growth Protection System (MGPS) bekerja dengan prinsip elektrolisis yang bekerja memberi perlindungan secara terus menerus. Dengan penggabungan dua sistem yaitu instalasi pipa anti-fouling dan supresi korosi (corrosion suppression). Dengan mengontrol tegangan rendah dari panel power supply yang di salurkan ke sebuah anoda yang terhubung langsung dengan cairan (air laut) pada jaringan pipa untuk mencegah pertumbuhan marine growth dan meminimalisir pengaruh keasaman kadar cairan terhadap proses korosi di sepanjang instalasi pipa (Songjung-dong; 2010).

Elektrolisis merupakan proses kimia yang mengubah energi listrik menjadi energi kimia. Pada proses elektrolisis, katoda menjadi kutub negatif dan anoda menjadi kutub positif. Reaksi reduksi akan terjadi pada katoda dan reaksi oksidasi terjadi pada anoda. Elektrolisis air adalah proses penguraian senyawa air $\left(\mathrm{H}_{2} \mathrm{O}\right)$ menjadi oksigen $\left(\mathrm{O}_{2}\right)$ dan hidrogen gas $\left(\mathrm{H}_{2}\right)$ dengan memanfaatkan arus listrik yang melewati air tersebut. Pada katoda, dua molekul air bereaksi dengan menangkap dua elektron, tereduksi menjadi ion hidrokida $\left(\mathrm{OH}^{-}\right)$dan gas $\mathrm{H}_{2}$. Di sisi lain pada anoda, dua molekul air lain terurai menjadi gas oksigen $\left(\mathrm{O}_{2}\right)$, melepaskan 4 ion $\mathrm{H}^{+}$serta mengalirkan elektron ke katoda. $\mathrm{OH}^{-}$dan Ion $\mathrm{H}^{+}$mengalami penetralan sehingga kembali terbentuk beberapa molekul air. Reaksi secara keseluruhan yang sebanding dari elektrolisis air dapat dijelaskan sebagai berikut: $2 \mathrm{H}_{2} \mathrm{O}(l) \rightarrow$ $2 \mathrm{H}_{2}(g)+\mathrm{O}_{2}(g)$

(Wikipedia; 2019).

Selama melakukan penelitian di atas kapal MT. Ketaling ditemukan bahwa perawatan dan pengoperasian 
MGPS yang tidak dilakukan secara optimal yang menyebabkan terjadinya penurunan fungsi kinerja dalam menghambat laju pertumbuhan marine growth. Hal tersebut menyebabkan tumbuhnya karat yang berlebih dan penyumbatan pada beberapa pipa di tube condenser maupun cooler yang mengakibatkan kurang optimalnya kinerja daripada condenser dan cooler itu sendiri.

Tujuan dari penelitian adalah untuk mengetahui faktor penyebab dan dampak dari turunnya kinerja marine growth Protection system (MGPS) pada sistem pendinginan kapal sebagai upaya yang harus dilakukan dalam mengoptimalkan kinerja marine growth Protection system (MGPS)

\section{METODE}

Penelitian ini menggunakan metode penelitian deskriptif kualitatif untuk mengungkap dan menjelaskan permasalahan tentang turunnya kinerja marine growth Protection system (MGPS) pada sistem pendinginan kapal.

Fokus dari penelitian ini adalah mengetahui faktor dan dampak dari turunnya kinerja marine growth Protection system (MGPS) pada sistem pendinginan kapal serta upaya yang harus dilakukan.

Lokasi penelitian ini bertempat dilaksanakannya penelitian yaitu kapal MT. Ketaling milik perusahaan PT Selama 11 Bulan 12 hari terhitung sejak 20 Oktober 2017 sampai dengan 2 Oktober 2018. Pertamina (PERSERO). Rute pelayaran meliputi daerah Indonesia yaitu Balikpapan, Kota Baru, Kasim, Ambon, Tg. Perak, Pontianak, Cilacap, Semampir, Tg. Wangi, Manggis, Panjang, Merak, Dan Sorong.

Sumber data yang digunakan berupa sumber data primer dan sumber data sekunder. Sumber data primer didapatkan dengan cara pencatatan, pengamatan, serta wawancara dengan crew mesin kapal MT. Ketaling. Sumber data sekunder didapatkan melalui studi pustaka manual book, data-data yang ada di kapal yang berkaitan dengan MGPS.

Pengumpulan data pada penelitian ini dengan teknik studi pustaka, dokumentasi, serta riset lapangan.

Data yang didapat dari Riset lapangan yaitu dengan cara observasi langsung pada obyek yang diteliti di kapal MT. Ketaling. Serta dengan dilakukannya wawancara kepada crew mesin kapal MT. Ketaling mengenai objek tersebut.

Data yang didapat dari studi pustaka yaitu dengan cara mencatat, meneliti serta mempelajari manual book maupun data-data yang ada di atas kapal yang berhubungan langsung dengan permesinan MGPS. Data dari dokumentasi didapatkan dengan cara memfoto setiap kegiatan yang berkaitan dengan perawatan, pengecekan, dan overhaul.

Teknik yang digunakan untuk menganalisis data dalam penelitian ini adalah fishbone diagram. Dengan menggunakan jenis kategori man (manusia), machine (permesinan), material (bahan), method (prosedur), measurement (pengukuran), dan mother nature (lingkungan). Lalu untuk mengidentifikasi prioritas masalah yang diteliti menggunakan SHEL (Softwere, Hardwere, Environment, Livewere).

Alur pikir penelitian dimulai dari turunnya kinerja marine growth Protection system (MGPS) pada sistem pendinginan, kemudian studi secara teori dan lapangan mengenai permesinan tersebut dan diperoleh factor penyebab dan dampak dari turunnya kinerja marine growth Protection system (MGPS) pada sistem pendinginan dan upaya yang harus dilakukan sehingga kinerja marine growth Protection system (MGPS) menjadi optimal, hal tersebut dapat dilihat pada gambar 1 dibawah ini: 


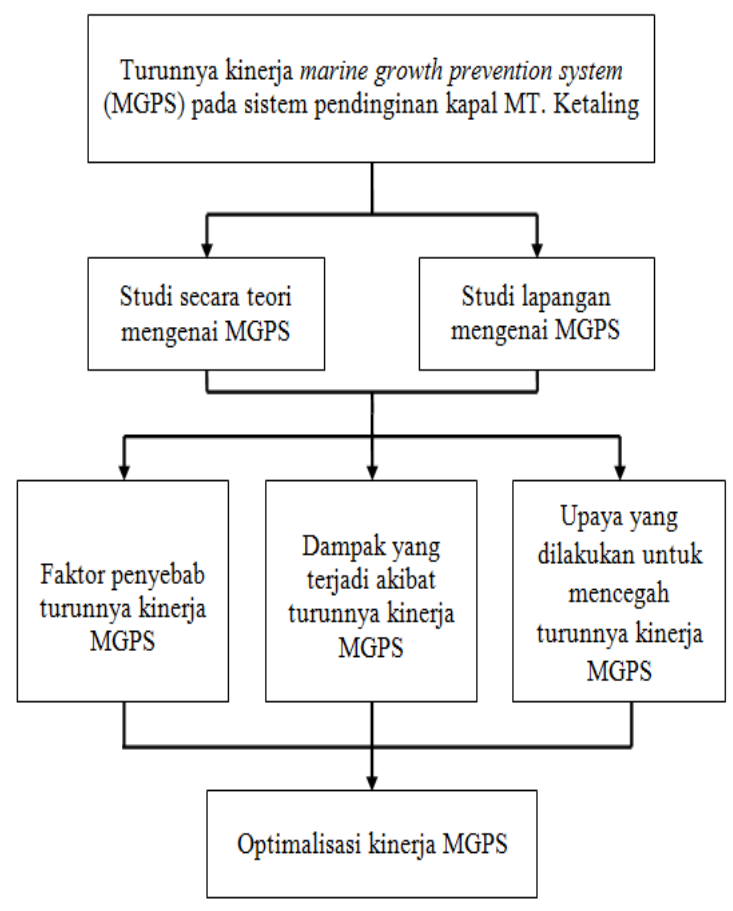

Gambar 1. Alur Pikir Penelitian

\section{HASIL DAN PEMBAHASAN}

Fakta yang terjadi pada permesinan

Marine Growth Protection System (MGPS) ketika penulis melaksanakan praktek laut selama 12 bulan di kapal MT. Ketaling yaitu bahwa permesinan tersebut sama sekali tidak ada perawatan dan pengoperasian yang sesuai standar dari masalah ini menyebabkan kegagalan fungsi pada komponen untuk menaikan suplai tegangan listrik pada saat perubahan status kapal dari maneuvering ke sea going, pada saat perubahan status ini arus listrik pada Marine Growth Protection System (MGPS) harus ditambah dengan cara menaikan suplai tegangan listrik dan harus disesuaikan dengan kuantitas dan kecepatan air laut yang masuk melalui sea chest.

Karena adanya kegagalan fungsi pada komponen tersebut anoda dan katoda yang menghasilkan arus listrik lemah menjadi tidak sempurna kerjanya kemudian menyebabkkan zat chlorine yang dihasilkan dari air laut dan arus listrik dari katoda dan anoda menjadi menurun sehingga kotoran dan biotabiota laut yang ikut masuk terhisap menuju sistem sistem pendingin tidak tercegah secara maksimal dan mengendap sehingga biota-biota laut tumbuh diantara pipa-pipa pendingin tersebut.

Menganalisis masalah adalah langkah awal penelitian yang digunakan untuk mencari jawaban sementara yang berkaitan dengan timbulnya masalah beralaskan rumusan masalah yang diteliti, masalah-masalah yang pada akhirnya akan dibahas pada pembahasan masalah didapatkan melalui analisisanalisis tersebut. Faktor-faktor yang disajikan akan dirangkum kedalam kategori-kategori yang digunakan dalam pembahasan masalah. Kategori tersebut adalah Man Power (pekerja fisik atau tenaga kerja) / Mind Power (pekerjaan pikiran: ide, pola pikir, saran, dan sebagainya), Machine (mesin atau teknologi), Material (termasuk raw material, consumption atau bahan), Method (proses atau metode), Measurement (inspeksi atau pengukuran), dan Mother Nature (lingkungan dimana kapal berada).

Faktor yang menyebabkan turunnya kinerja Marine Growth Protection System (MGPS) pada system pendinginan kapal adalah:

1. Kategori Method (proses/prosedur) yaitu pelaksanaan jadwal perawatan yang tidak tepat waktu dan tidak lengkapnya data-data pada manual book.

2. Kategori Machine (mesin) yaitu penggunaan anoda yang melebihi batas umur pemakaian, menempelnya deposit yang menutupi permukaan anoda, dan terputus atau terkelupasnya kabel pada sistem MGPS.

3. Kategori Mother Nature (lingkungan) yaitu getaran berlebih pada operasional kapal, lingkungan kapal, dan unsur yang ada pada air laut.

4. Kategori Man (manusia) yaitu kurangnya pengetahuan, kurangnya keterampilan, dan kurangnya komunikasi.

5. Kategori Measurement (pengukuran) yaitu kurang tepatnya pengaturan tegangan output pada MGPS. 
6. Kategori Material (bahan) yaitu kualitas komponen tidak sesuai standar.

Dampak yang ditimbulkan akibat turunnya kinerja Marine Growth Protection System (MGPS) pada system pendinginan kapal menurut faktorfaktornya adalah:

1. Kategori Method (proses / prosedur)

a) Pelaksanaan jadwal perawatan yang tidak tepat waktu, berdampak pada usia kerja dari anoda menjadi berkurang, terhambatnya pengoperasian MGPS, dan kerusakan pada sistem maupun komponen lainnya.

b) Tidak lengkapnya data-data pada manual book, sehingga mengakibatkan kurangnya informasi-informasi penting pada permesinan tersebut, kurangnya landasan teori yang digunakan untuk melaksanakan perawatan, overhaul, dan pengoperasian.

2. Kategori Machine (mesin)

a) Penggunaan anoda yang melebihi batas umur pemakaian, yang berdampak arus konstan pada masing-masing anoda tidak dapat dipertahankan dengan sebagaimana mestinya, anoda yang sudah terkikis habis dapat mempengaruhi jumlah ion yang dihasilkan pada proses elektrolisisi air laut.

b) Menempelnya deposit yang menutupi permukaan anoda, berpengaruh pada besarnya tegangan pada setiap anoda.

c) Terputus atau terkelupasnya kabel pada sistem MGPS, sehingga arus yang mengalir ke anoda tidak maksimal, arus listrik tidak tersampaikan ke anoda, inti kabel (tembaga) menempel pada konduktor lain dan mengakibatkan short circuit atau arus pendek.

3. Kategori Mother Nature (lingkungan)

a) Getaran berlebih pada operasional kapal, sehingga berdampak pada lepasnya baut pengikat kabel sehingga kabel bergesekan dengan material lain dan menyebabkan kulit kabel terkelupas.

b) Lingkungan kapal, dampaknya jumlah biota laut yang berlebihan mempengaruhi efisiensi kinerja sistem MGPS, dan unsur yang terdapat pada air laut mempengaruhi nilai resistivitas aliran listrik.

c) Unsur yang ada pada air laut, berdampak pada proses penghantaran arus listrik dan jumlah ion yang dihasilkan proses elektrolisis menjadi terpengaruh atau tidak maksimal.

4. Kategori Man (manusia)

a) Kurangnya pengetahuan, berdampak pada kelalaian dalam melaksanakan perawatan, overhaul, dan tidak sesuainya pengoperasian permesinan sesuai dengan SOP.

b) Kurangnya keterampilan, berdampak pada kurangnya ketelitian dalam melakukan perawatan, overhaul, dan pengoperasian yang tidak sesuai standar.

c) Kurangnya komunikasi, sehingga terjadi miss understanding atau salah paham saat pengoperasian permesinan MGPS, dan terjadinya kelalaian mengenai informasi penting pada permesinan tersebut.

5. Kategori Measurement (pengukuran) Adapun dampak yang terjadi akibat kurang tepatnya pengaturan tegangan output yaitu: Arus konstan pada masing-masing anoda tidak dapat dipertahankan dengan sebagaimana mestinya, tegangan yang kurang sesuai dengan kondisi dan lingkungan kapal dapat mempengaruhi ion yang dihasilkan pada proses elektrolisis air laut.

\section{Kategori Material (bahan)}

Adapun dampak yang terjadi akibat kualitas komponen yang digunakan tidak sesuai standar atau 
palsu yaitu akan berdampak pada umur kerja, kinerja, keselamatan, dan hasil dari suatu permesinan tersebut. Dan apabila bahan yang digunakan sebagai material salah maka akan berpengaruh pada perbedaan fungsinya juga.

Upaya yang perlu dilakukan untuk mencegah faktor-faktor turunnya kinerja Marine Growth Protection System (MGPS) pada sistem pendinginan kapal adalah:

1. Pada kategori Method (proses / prosedur), upaya yang perlu dilakukan adalah memperbaiki dan menjalankan plan maintenance system, dan meningkatkan kedisiplinan dalam melakukan perawatan, sehingga jadwal perawatan menjadi tepat waktu. Tidak lengkapnya data-data pada manual book dapat diperbaiki dengan dengan mencari bagianbagian manual book yang hilang atau meminta manual book yang baru pada maker atau perusahaan.

2. Pada kategori Machine (mesin), upaya yang perlu dilakukan adalah: a) mengganti anoda sesuai dengan batas umur pemakaian pada manual book, sehingga penggunaan anoda yang melebihi batas umur pemakaian; b) membersikan permukaan anoda dari kotoran yang menutupi atau dengan cara mengganti anoda dengan yang baru; c) mengecek setiap line kabel secara visual dan menggunakan mager tester untuk menemukan adanya kabel yang terputus atau tidak, jika sudah menemukan kabel yang rusak maka tutup kabel yang rusak dengan solasi atau diganti dengan yang baru.

3. Pada Kategori Mother Nature (lingkungan), upaya yang perlu dilakukan adalah: a) memperkecil amplitudo eskitasi gaya dorong baling-baling (thrust), merubah besarnya RPM baling-baling, merubah jumlah daun baling- baling, dan merubah frekuensi natural struktur yang beresonansi sehingga tidak ada getaran yang berlebih pada operasional kapal; b) menaikkan tegangan output sampai kadar biota pada suatu perairan berkurang atau terlewati; dan c) menaikkan tegangan output sampai sehingga proses elekrolisis berjalan normal.

4. Pada Kategori Man (manusia), upaya yang perlu dilakukan adalah memberikan pengarahan pada engineer mengenai permesinan MGPS, memberikan training pada engineer mengenai permesinan MGPS, dan melaksanakan safety meeting dan mencatat info-info pada papan prngumuman engineer agar semua engineer mengetahui info terbaru mengenai permesinan tersebut. Denagn demikian pengetahuan, ketrampilan dan komunikasi dari engineer dapat meningkat.

5. Pada Kategori Measurement (pengukuran), upaya yang perlu dilakukan yaitu dengan memberikan petunjuk Standart Operasional Procedure (SOP) pada panel MGPS, dan memberikan pemahaman pada setiap engineer mengenai permesinan MGPS.

6. Pada Kategori Material (bahan), upaya yang perlu dilakukan yaitu dengan menyeleksi sumber dari komponen, mengecek dokumen dari pembelian, pemeriksaan data penerimaan komponen, serta memeriksa tempat penyimpanannya.

Setelah dianalisa menggunakan metode fishbone selanjutnya penulis menganalisa dan mengidentifikasi prioritas masalah yang paling mungkin menjadi penyebab turunnya kinerja Marine Growth Protection System (MGPS) dan mengkategorikan ke dalam metode SHEL (Software, Hardware, Environment, dan Livewere) sesuai dengan kategorinya masing-masing. 
Untuk menemukan prioritas masalah dari turunnya kinerja Marine Growth Protection System (MGPS) pada sistem pendinginan di kapal, penulis menyimpulkan data-data dari hasil observasi penelitian tersebut lalu diperkuat dengan data-data hasil wawancara dan studi pustaka sehingga dapat ditemukannya 4 faktor yang menjadi prioritas masalah yang menjadi penyebab turunnya kinerja Marine Growth Protection System (MGPS) pada system pendinginan kapal dan di kategorikan menurut kategori pada metode SHEL sebagai berikut:

1. Faktor turunnya kinerja Marine Growth Protection System (MGPS) menurut kategori Software yaitu kurang tepatnya pengaturan tegangan pada MGPS.

Adapun dampak yang terjadi akibat kurang tepatnya pengaturan tegangan output yaitu: Arus konstan pada masing-masing anoda tidak dapat dipertahankan dengan sebagaimana mestinya, tegangan yang kurang sesuai dengan kondisi dan lingkungan kapal dapat mempengaruhi ion yang dihasilkan pada proses elektrolisis air laut. Upaya yang perlu dilakukan yaitu dengan memberikan petunjuk Standart Operasional Procedure (SOP) pada panel MGPS, dan memberikan pemahaman pada setiap engineer mengenai permesinan MGPS. Pengaturan tegangan output pada Marine Growth Protection System (MGPS) harus disesuaikan dengan kondisi kapal dan lingkungan dimana kapal berada.

2. Faktor turunnya kinerja Marine Growth Protection System (MGPS) menurut kategori Hardware yaitu penggunaan anoda yang sudah melebihi batas umur.

Dampaknya yaitu: Arus konstan pada masing-masing anoda tidak dapat dipertahankan dengan sebagaimana mestinya, anoda yang sudah terkikis habis dapat mempengaruhi jumlah ion yang dihasilkan pada proses elektrolisisi air laut. Upaya yang perlu dilakukan yaitu dengan mengganti anoda sesuai dengan batas umur pemakaian pada manual book.

3. Faktor turunnya kinerja Marine Growth Protection System (MGPS) menurut kategori Environment yaitu kondisi dan unsur air laut pada lingkungan dimana kapal berada.

Dampaknya yaitu: Jumlah biota laut yang berlebihan mempengaruhi efisiensi kinerja sistem MGPS, dan unsur yang terdapat pada air laut mempengaruhi nilai resistivitas aliran listrik. Upaya yang perlu dilakukan yaitu dengan cara menaikkan tegangan output sesuai panduan pada manual book sampai kadar biota pada suatu perairan berkurang atau terlewati.

4. Faktor turunnya kinerja Marine Growth Protection System (MGPS) menurut kategori Lifeware yaitu kurangnya pengetahuan seorang engineer mengenai permesinan MGPS.

Dmpaknya yaitu: Kelalaian dalam melaksanakan perawatan, overhaul, dan tidak sesuainya pengoperasian permesinan sesuai dengan SOP. Upaya yang perlu dilakukan yaitu dengan memberikan training dan ujian sebelum naik kapal serta memberikan familiarisasi permesinan di atas kapal.

\section{SIMPULAN}

Fakor penyebab turunnya kinerja Marine Growth Protection System (MGPS) pada sistem pendinginan kapal adalah: a) Kurang tepatnya pengaturan tegangan pada MGPS; b) Penggunaan anoda yang sudah melebihi batas umur; c) Kondisi dan unsur air laut pada lingkungan dimana kapal berada; dan d)kurangnya pengetahuan seorang engineer mengenai permesinan MGPS.

Upaya yang dilakukan untuk mengatasi faktor penyebab turunnya kinerja Marine Growth Protection System (MGPS) pada sistem pendinginan kapal adalah memberikan petunjuk Standart Operasional Procedure (SOP) pada panel 
MGPS dan memberikan pemahaman pada setiap engineer mengenai permesinan MGPS, Mengganti anoda dengan yang baru, Menaikkan tegangan output hingga 0,20 amp sampai kadar biota pada suatu perairan berkurang atau terlewati dan melakukan diskusi dengan masalah yang terjadi dan membaca manualbook yang tersedia.

\section{DAFTAR PUSTAKA}

Gapsari, F. (2017). Pengantar Korosi. Malang: Universitas Brawijaya.

Hernandar, A. (2009). Marine Growth dan Pencegahannya. https://aguzher.wordpress.com/200 9/03/16/marine-growth-danpencegahannya/.

Handoyo.J. (2015). Mesin Diesel Penggerak Utama Kapal Ahli Tehnik Tingkat 3. jakarta Utara: Djangkar.

Maanen, P, V. (2002). Motor Diesel Kapal. Noutech.

NSOS. (2006). Manajemen Perawatan dan Perbaikan. Jakarta: Direktur Jendral Perhubungan Laut.

Songjung-dong. (2010). Final Drawing \& Operation Manual Anti Fouling System (MGPS). Korea: KC.LTD.

Van Der Ham, C. J. (2003). Meteorologi dan Oceanografi untuk Pelayaran. Belanda: Hollandia. 